\title{
PENERAPAN KEBIJAKAN PENGELOLAAN LINGKUNGAN MENUJU UDARA BERSIH DI KERAJINAN PERAK DESA CELUK PROVINSI BALI
}

\author{
Arian Pramudi ${ }^{1}$, Nadiroh ${ }^{2}$ \\ ${ }^{I}$ Manajemen Lingkungan, Pascasarjana Universitas Negeri Jakarta, Komplek Universitas Negeri Jakarta \\ Gedung M. Hatta, Jl. Rawamangun Muka, Jakarta Timur, Indonesia 13220, email: apramudi@gmail.com \\ ${ }^{2}$ Dosen Manajemen Lingkungan, Pascasarjana Universitas Negeri Jakarta, Komplek Universitas Negeri \\ Jakarta Gedung M. Hatta, Jl. Rawamangun Muka, Jakarta Timur, Indonesia 13220
}

\begin{abstract}
Abstrak
Desa Celuk termasuk wilayah Kecamatan Sukawati, kabupaten Gianyar Provinsi Bali. Desa Celuk Bali terkenal karena hasil dari pengrajin emas dan perak, hasil kerajinan rumahan tersebut memang memiliki mutu dan cita rasa seni bernilai tinggi. Kegiatan pembuatan kerajinan perak salah satunya adalah kegiatan penyepuhan (elektoplating). Proses elektroplating selain menghasilkan produk yang berguna, menghasilkan pula limbah padat, emisi gas dan cair. Limbah berupa emisi gas pada umumnya berasal dari penguapan larutan elektrolit, solven, uap asam, maupun cairan pembersih. Tujuan dalam tulisan ini adalah bagaimana penerapan kebijakan pengelolaan lingkungan pengendalian pencemaran udara menuju udara bersih pada pengrajin perak di Desa Celuk. Dengan metode menggunakan teknik pengumpulan data dengan instrumen serta wawancara. Dari hasil kuesioner dan wawancara, didapatkan hasil $0 \%$ untuk indikator penerapan kebijakan pengelolaan lingkungan pengendalian pencemaran udara dan hanya $25 \%$ untuk indikator udara bersih
\end{abstract}

Kata kunci : Pengrajin perak, desa celuk, kebijakan pengelolaan lingkungan, udara bersih

\begin{abstract}
The village of Celuk belongs to Sukawati sub-district, Gianyar regency of Bali province. Celuk Bali Village is famous for the results of gold and silver craftsmen, the home-made crafts do have the quality and taste of high-value art. Silvery handicraft activity one of them is the activity of plating (elektoplating). Electroplating process in addition to producing useful products, also produce solid waste, gas and liquid emissions. Waste in the form of gas emissions generally comes from the evaporation of electrolyte, solvent, acid vapor, and cleaning fluids. The purpose of this paper is how the implementation of environmental management policy of air pollution control towards clean air to silver artisans in Celuk Village. By using methods of data collection with instruments and interviews. From the results of questionnaires and interviews, $0 \%$ results obtained for indicators of the implementation of environmental management policies of air pollution control and only $25 \%$ for the indicator of clean air
\end{abstract}

Keywords: Silver craftsman, celuk village, environmental management policy, clean air 


\section{PENDAHULUAN}

Masalah pencemaran udara utama saat ini adalah terkait kendaraan, emisi sulfur, hujan asam, pencemaran ozon. Debu udara yang dihasilkan oleh pembajakan lahan, degradasi lahan dan kebakaran hutan telah menyebabkan masalah dan dapat merusak. Pencemaran atmosfer dengan gas rumah kaca (karbon dioksida, metana, dan beberapa gas lainnya). Polusi dari industri dapat mempengaruhi lingkungan pada jarak yang cukup jauh dari luar, salah satu dampaknya adalah hujan asam (Barrow C.J., 2006)

Pencemaran udara adalah kehadiran di atmosfer satu atau lebih kontaminan seperti debu, asap, gas, kabut, bau, atau uap dalam jumlah dan karakteristik dan jangka waktu yang dapat membahayakan kehidupan manusia, tumbuhan, hewani atau bangunan (Mc Graw Hill, 2003)

Pencemaran udara terjadi pada banyak tahap dalam siklus hidup produk dan layanan, yaitu dari ekstraksi bahan baku, perolehan energi, produksi dan pembuatan, penggunaan, penggunaan kembali, daur ulang, sampai pembuangan akhir. Emisi yang dihasilkan mengalami beberapa jenis transformasi fisik dan kimia dan berkontribusi terhadap berbagai dampak kesehatan dan lingkungan, termasuk kemerosotan kualitas udara, tekanan toksik pada kesehatan manusia dan ekosistem, asap, penipisan lapisan ozon, perubahan iklim, penurunan sumber daya udara, dan kebisingan (Pennington et al., 2004).

Kebijakan pengelolaan lingkungan mengenai pengendalian pencemaran udara yaitu PP No. 41/1999 mendefinisikan sumber pencemaran udara sebagai setiap usaha dan atau kegiatan yang mengeluarkan bahan pencemar ke udara dengan menyebabkan udara tidak berfungsi sebagaimana mestinya, dan kemudian peraturan pemerintah ini menggolongkan sumber pencemaran udara atas lima, yakni

a. Sumber bergerak : sumber emisi yang bergerak atau tetap pada suatu tempat yang berasal dari kendaraan bermotor

b. Sumber bergerak spesifik : serupa dengan sumber bergerak namun berasal dari kereta api, pesawat terbang, kapal, laut dan kendaraan berat lainnya.

c. Sumber tidak bergerak : sumber emisi yang tetap pada suatu tempat.

d. Sumber tidak bergerak spesifik : serupa dengan sumber tidak bergerak namun berasal dari kebakaran hutan dan pembakaran sampah.

e. Sumber gangguan: sumber pencemar yang menggunakan media udara atau 
padat untuk penyebarannya, sumber ini berupa dari kebisingan, getaran,

Desa Celuk termasuk wilayah Kecamatan Sukawati, kabupaten Gianyar Provinsi Bali. Desa Celuk Bali terkenal karena hasil dari pengrajin emas dan perak, hasil kerajinan rumahan tersebut memang memiliki mutu dan cita rasa seni bernilai tinggi.

Kerajinan perak memiliki berbagai macam jenis menurut cara pembuatanya masing-masing yang dibagi menjadi 3 jenis yaitu: (a) Perak Cetak: merupakan proses pembuatan yang dilakukan dengan cara menggunakan cetakan agar dapat membuat produk dalam jumlah yang banyak dan waktu yang cepat. Proses ini awalnya dilakukan dengan cara mencairkan bahan baku lalu menaruhnya kedalam cetakan dengan bentuk sesuai yang diinginkan lalu ketika sudah tercetak dilakukan proses akhir pengamplasan dan pembersihan cetakan - cetakan yang kurang rapi. (b) Buatan Tangan (Handmade). Merupakan proses pembuatan kerajinan perak dengan cara dari awal hingga akhir pembuatan dilakukan murni hasil buatan tangan manusia. Awalnya proses ini dilakukan dengan melebur perak lalu dibentuk pola sesuai dengan perhiasan atau kerajinan yang akan dibuat, lalu setelah itu dimulai proses pengukiranya, setelah proses pengukiran selesai perhiasan atau kerajinan direndam dengan asam fulkas kemudian diamplas atau dihaluskan. (c) Perak Buatan Mesin: Merupakan proses pembuatan kerajinan yang hampir mirip dengan perak cetak, namun perak buatan mesin membuat kerajinan menggunakan mesin, biasanya mesin ini menghasilkan kalung, rantai gelang, dan sebagainya. Kerajinan perak di Desa celuk terkenal karena kerajinan khas Balinya yang dibuat langsung dengan tangan (handmade) dimana keunikan tersebut terletak pada kerumitan ukiranukiran khas Bali yang membuat harga kerajinan perak tersebut bernilai tinggi. Namun karena mahal dan tingginya harga kerajinan perak tidak semua kalangan masyarakat mampu membeli kerajinan dan perhiasan perak. (I Ketut S, 2017)

Kegiatan pembuatan kerajinan perak salah satunya adalah kegiatan penyepuhan (elektoplating). Proses elektroplating selain menghasilkan produk yang berguna, menghasilkan pula limbah padat, emisi gas dan cair. Limbah padat berasal dari proses penghilangan kerak, polishing, maupun kotoran sisa pada bakelektroplating. Limbah berupa emisi gas pada umumnya berasal dari penguapan larutan elektrolit, solven, uap asam, maupun cairan pembersih. Limbah cair berupa air limbah yang berasal dari pencucian, pembersihan dan proses elektroplating. Air limbah mengandung logam-logam terlarut, solven 
dan senyawa organik maupun anorganik terlarut lainnya

Hasil penelitian (Nur Ainun S., 2003) mengenai kesehatan kerja home industry tembaga di Kota Gede Yogyakarta yaitu keadaan kesehatan lingkungan kerja dan perilndungan kesehatan pekerja dilingkungan home-home industri tembagaKotagede cukup memprihatinkan. Faktor pemicunya adalah ketiadaan sistem pengendalian kesehatan lingkungan kerja dan perlindungan kesehatan pekerja baik oleh dinas pemerintah kota setempat maupun pengusahamenyikapi keadaan kesehatan lingkungan keija dan perlindungan kesehatan pekerja yang buruk tersebutmakadibutuhkan beberapa teknik penyehatan yang memerlukan prioritas dan ditujukan untuk: pengendalian pencemaran lingkungan dan peningkatan hygiene perusahaan dan kesehatan/keselamatan kerja di dalam ruang lingkup lingkungan kerja.

Hasil penelitian (Alpano P, Nadiroh dan Rukaesih, 2014) mengenai evaluasi implementasi kebijakan program pengembangan lingkungan untuk meningkatkan kualitas lingkungan di PT. Krakatau Steel, Kota Cilegon yaitu jika proses implementasi kebijakan Program Pengembangan Lingkungan berjalan dengan baik, maka dapat meningkatkan kualitas lingkungan di daerah sekitar
DOI : doi.org/10.21009/jgg.091.02

kawasan industri. Namun, proses implementasi kebijakan membutuhkan tahapan yang sistematis. Masalah utama dari implementasi kebijakan ini adalah: 1) Proses perencanaan dalam hal masalah pemetaan lingkungan tidak berjalan dengan baik di lapangan, dan juga kurangnya pemahaman tentang perusahaan terhadap kebutuhan masyarakat lokal tanpa adanya pemantauan dini lingkungan kondisi; 2) Proses pemantauan belum mampu menampung data perkembangan pembangunan dan tidak memaksimalkan sosialisasi Program Pengembangan Lingkungan dengan baik di masyarakat setempat karena masih ada program yang tidak berjalan sebagaimana mestinya.

Sesuai dengan latar belakang yang telah diuraikan tersebut, maka perumusan masalah dalam tulisan ini yaitu bagaimana penerapan kebijakan pengelolaan lingkungan pengendalian pencemaran udara menuju udara bersih pada pengrajin perak di Desa Celuk

\section{METODOLOGI}

Penelitian ini menggunakan teknik pengumpulan data dengan instrumen serta wawancara. Instrumen penelitian berupa kuesioner dalam memperoleh data yang diperlukan. Instrumen penelitian adalah alat yang digunakan oleh penelitian dalam mengumpulkan data agar memudahkan 
mengumpulkan, mengolah, menyajikan data yang bermanfaat dalam menjawab masalah penelitian. Sampel dalam penelitian ini yaitu para pengrajin perak di Desa Celuk. Data yang diperoleh melalui kuesioner disajikan dengan menggunakan analisis secara deskriptif untuk dibuat kesimpulan. Teknik sampling yang digunakan untuk penentuan sampel adalah random sampling yaitu pengambilan sampel secara acak. Setiap instrumen penelitian berpedoman pada konsepsional yang meliputi definisi konseptual, definisi operasional, kisi-kisi instrumen penelitian.

\section{HASIL DAN PEMBAHASAN}

Komponen penerapan kebijakan pengelolaan lingkungan pengendalian pencemaran udara meliputi :

1. Udara ambien adalah udara bebas yang dihirup setiap hari oleh makhluk hidup. Kualitas udara sekitar bisa dikatakan menurun yang diketahui dari hasil pengukuran kualitas udara sekitar
(Kurniawati et.al., 2015). Sesuai dengan Peraturan Pemerintah No. 41 Tahun 1999 tentangPengendalian Pencemaran Udara, udara ambien adalah udara bebas di permukaan bumi pada lapisan troposfir yang berada di dalam wilayah yurisdiksi Republik Indonesia yang dibutuhkan dan mempengaruhi kesehatan manusia, makhluk hidup dan unsur lingkungan hidup lainnya

2. Emisi sumber tidak bergerak yaitu menurut (WHO, 2006) pembakaran bahan bakar fosil pada cerobong proses sumber tidak bergerak merupakan sumber utama emisi polutan di sebagian besar negara. Pembakaran suhu tinggi merupakan sumber oksida nitrogen, dan juga sulfur dioksida jika belerang ada di bahan bakar. Pembakaran bahan bakar juga biasanya memancarkan VOC, terutama dari batu bara dan minyak, yang sulit terbakar sama sekali.

Tabel 1. Kisi-kisi intrumen

Variable

Indikator

Memiliki cerobong asap dan sesuai dengan ketentuan teknis 


\begin{tabular}{|l|l|}
\hline Kebijakan & Pengukuran kualitas udara pada sumber/cerobong \\
\cline { 2 - 2 } $\begin{array}{l}\text { Pengelolaan } \\
\text { Lingkunganpen }\end{array}$ & Pengukuran kualitas udara ambien \\
\cline { 2 - 2 } $\begin{array}{l}\text { gendalian } \\
\text { pencemaran } \\
\text { udara }\end{array}$ & Pengukuran emisi kendaraan operasional \\
\cline { 2 - 2 } & Pengendalian kebisingan pada sumber \\
\cline { 2 - 2 } Udara Bersih & Pengukuran kebisingan \\
\cline { 2 - 2 } & Kawasan dilarang merokok \\
\cline { 2 - 2 } & Alat pengendali emisi udara \\
\cline { 2 - 2 } & Bahan bakar ramah lingkungan \\
\cline { 2 - 2 } & Perbaikan pada mesin produksi \\
\hline
\end{tabular}

Dari hasil kuesioner dan wawancara, didapatkan hasil $0 \quad \%$ untuk indikatorpenerapankebijakan pengelolaan lingkungan pengendalian pencemaran udara dan hanya $25 \%$ untuk indikator udara bersih, dengan hasil yaitu :

1. Kegiatan usaha memiliki mesin/sumber yang menghasilkan pencemaran udara yang berasal dari kegiatan penyepuhan (solder) dan pematrian dengan logam kuningan sehingga menghasilkan emisi debu dan bahan kimia untuk pelarut dan cairan pembersih

2. Tidak memiliki cerobong asap

3. Tidak menggunakan peralatan pelindung (masker) untuk mengurangi dampak pencemaran udara

4. Tidak melakukan pengukuran kualitas udara pada sumber pencemar

5. Tidak melakukan pengkuran kualitas udara pada udara ambien (sekitar)

6. Tidak memiliki alat pengendali emisi udara
7. Menggunakan bahan bakar yang tidak ramah lingkungan yaitu solar untuk pematrian

8. Tidak ada keluhan warga terkait dampak pencemaran udara dari kegiatan produksi

9. Memiliki SOP dalam pembuatan kerajinan perak, yaitu SNI 925 adalah jenis ini merupakan yang paling umum digunakan untuk pembuatan kerajinandan perhiasan, dan juga telah ditetapkan sebagai standar perak internasional.Di Indonesia perak jenis ini sering juga disebut sebagai perak 925 karena perakmurni yang terkandung dalam sterling silver sebesar 92,5\%. Umumnya 7,5\%lainnya adalah campuran tembaga. Sterling silver ini memiliki keunggulanberatnya yang ringan dan mudah dibentuk.

10. Tidak melakukan perawatan pada mesin

11. Tidak melakukan kegiatan pembakaran sampah sisa produksi 
12. Tidak melakukan pengujian emisi pada kendaraan operasional

13. Memiliki sumber kebisingan dari kegiatan pembuatan lempengan dengan palu

14. Tidak memiliki peredam kebisingan pada sumber

15. Tidak melakukan pengukuan kebisingan

16. Masih diperbolehkan merokok didalam ruangan produksi
DOI : doi.org/10.21009/jgg.091.02

Sebagai bahan perbandingan, berdasarkan data pada tahun 2011 pengukuran kualitas udara ambien di Kabupaten Gianyar sebanyak 3 (tiga) titik oleh Kementerian LHK RI, didapatkan hasil hanya parameter PM10yang hasilnya melewati baku mutu, untuk hasil lainya yaitu:

\begin{tabular}{|c|l|c|c|c|c|}
\hline No & Parameter & $\begin{array}{c}\text { Hasil } \\
\text { pengukuran di } \\
\text { lokasi terminal } \\
\text { batu bulan }\end{array}$ & $\begin{array}{c}\text { Hasil } \\
\text { pengukuran di } \\
\text { lokasi pasar br. } \\
\text { Teges }\end{array}$ & $\begin{array}{c}\text { Hasil } \\
\text { pengukuran di } \\
\text { lokasi pertigaan } \\
\text { puri ubud }\end{array}$ & $\begin{array}{c}\text { Baku Mutu } \\
\text { (Sesuai Pergub } \\
\text { Provinsi Bali } \\
\text { No.8 Tahun 2007 }\end{array}$ \\
\hline 1 & $\mathrm{SO} 2$ & 209.57 & 246.85 & 263.38 & 900 \\
\hline 2 & $\mathrm{CO}$ & 759.36 & 809.72 & 796.3 & 30000 \\
\hline 3 & $\mathrm{NO} 2$ & 58.92 & 62.59 & 59.61 & 400 \\
\hline 4 & $\mathrm{PM} 10$ & 173.61 & 169.54 & 177.31 & 150 \\
\hline 5 & $\mathrm{~Pb}$ & 0.741 & 0.765 & 0.686 & 2 \\
\hline
\end{tabular}




\section{KESIMPULAN}

Desa Celuk termasuk wilayah Kecamatan Sukawati, kabupaten Gianyar Provinsi Bali. Desa Celuk Bali terkenal karena hasil dari pengrajin emas dan perak, hasil kerajinan rumahan tersebut memang memiliki mutu dan cita rasa seni bernilai tinggi. Kegiatan pembuatan kerajinan perak salah satunya adalah kegiatan penyepuhan (elektoplating). Proses elektroplating selain menghasilkan produk yang berguna, menghasilkan pula limbah padat, emisi gas dan cair. Limbah berupa emisi gas pada umumnya berasal dari penguapan larutan elektrolit, solven, uap asam, maupun cairan pembersih.

Kisi-kisi instrument untuk variabel kebijakan pengelolaan lingkungan pengendalian pencemaran udara yaitu dengan indikator :memiliki cerobong asap dan sesuai dengan ketentuan teknis, pengukuran kualitas udara pada sumber/cerobong, pengukuran kualitas udara ambien, pengukuran emisi kendaraan operasional, pengendalian kebisingan pada sumber, pengukuran kebisingan dan kawasan dilarang merokok. Untuk variabel menuju udara bersih dengan indikator : alat pengendali emisi, bahan bakar ramah lingkungan, perbaikan pada mesin produksi dan pembakaran sisa sampah.
Dari hasil kuesioner dan wawancara, didapatkan hasil $0 \%$ untuk indikator penerapan kebijakan pengelolaan lingkungan pengendalian pencemaran udara dan hanya $25 \%$ untuk indikator udara bersih

\section{DAFTAR PUSTAKA}

Alpano Priandes, Nadiroh \& Rukaesih. (2014). Evaluasi implementasi kebijakan program pengembangan lingkungan untuk meningkatkan kualitas lingkungan di PT. Krakatau Steel, Kota Cilegon. Jurnal Green Growth dan Environmental Management Vol.3 No. 1

Barrow, C.J. (2006). Environmental Management For Sustainable Development. New York : Routledge

I Ketut Sudiana. (2017). Analisis Pendapatan Pengrajin Perhiasan di Desa Celuk (Studi Perbandingan Pengrajin Perak dan Pengrajin Alpaka). Jurnal Ekonomi Pembangunan Universitas Udayana. Vol.6 No.8

Kurniawati dkk. (2015). Pengelompokan Kualitas Udara Ambien Menurut Kabupaten/Kota di Jawa Tengah Menggunakan Analisis Klaster. Jurnal Gaussian Vol.4 No.2 Hal. 393-402

Mc-Graw Hill Companies. (2003). Dictionary of Environmental Science

Nur Ainun Simangunsong. (2003). Kesehatan Lingkungan Home Industri Tembaga Kotagede 
Yogyakarta. Jurnal Hukum No.24 Vol.10 p. 164-189

Pennington D.W et.al. (2004). Life Cycle Assesment Part 2 : Current Impact Assesment Practice. Environmental International, 721-739

Peraturan Pemerintah No. 41 Tahun 1999 Tentang Pengendalian Pencemaran Udara
Peraturan Gubernur Bali No. 8 Tahun 2007 Tentang Baku Mutu Lingkungan Hidup dan Kriteria Kerusakan Lingkungan Hidup

World Health Organization. (2006). Air Quality GuidelinesGlobal Update 2005

http://datin.menlh.go.id/datalingkungan/slhd-udara/ 